\title{
Application of Fuzzy Controller for Improvement of Power Quality using UPQC
}

\author{
M Sonia ${ }^{1}$ | Kundeti Krishna Rao ${ }^{2}$ \\ ${ }^{1}$ PG Student, Dept of EEE, Vikas Group of Institutions, Vijayawada, India \\ ${ }^{2}$ Assistant Professor, Dept of EEE, Vikas Group of Institutions, Vijayawada, India
}

To Cite this Article

M Sonia and Kundeti Krishna Rao, "Application of Fuzzy Controller for Improvement of Power Quality using UPQC", International Journal for Modern Trends in Science and Technology, 6(8): 27-30, 2020.

\section{Article Info}

Received on 02-June-2020, Revised on 26-June-2020, Accepted on 23-July-2020, Published on 28-July-2020.

\section{ABSTRACT}

Generally, one of the custom power device in FACTS called unified power quality conditioner, which is used to compensate the voltage and current-related Power Quality issues in the distribution systems. The proposed UPQC technology have an advantage of reduced dc-link voltage without compromising its compensation capability. This new method also helps to meet the requirement of dc-link voltage for the shunt and series active filters of the UPQC. This type of topology has a capacitor in series with the interfacing inductor across the shunt active filter for filtering purpose, and the system neutral is also considered and directly connected to neutral of distribution system avoid the requirement of the fourth leg in the voltage source inverter. This paper also presents a concept for improving power quality of a power distribution system such as an FUZZY logic controller along with the UPQC control strategy. The simulation results are compared for both conventional PI controller and FUZZY controller.

\section{INTRODUCTION}

In the advancement of power semiconductor devices, such as thyristors, Gate Turn off thyristors, Insulated Gate Bipolar Transistors and many more devices, which are used to control electric power.

In three phase systems, the power electronics devices could also cause unbalances in voltage and draw excessive neutral currents due to their disturbances. Due to because of these injected harmonics, reactive power burden, unbalance, and excessive neutral currents causes efficiency reduction and poor power factor. Therefore, improvement of power quality is one of the important issue since many loads at various distribution ends. Basically, the term Power Quality mainly deals with problems occurred in the system like improvement of voltage levels at the Point of Common Coupling (PCC) for various distribution voltage levels irrespective of voltage fluctuations, maintaining near unity power factor power drawn from the supply, blocking of voltage and current unbalance from passing upwards from various distribution levels, reduction of voltage and current harmonics in the system and suppression of excessive supply neutral current. Conventionally, passive LC filters has been used but these devices have the demerits of fixed compensation, large size, ageing and resonance. Nowadays these constraints cannot be overcome otherwise, while maintaining the required system stability, by mechanical means without lowering the useable transmission capacity. By providing added flexibility, FACTS controller can enable a line to carry power closer to its thermal rating. Mechanical switching needs to be supplemented by rapid-response power electronics 13]. The facts technology can certainly be used to overcome any to the stability limits, in which case the ultimate limits would be thermal and dielectric. 


\section{UNIFIED POWER FLOW CONTROLLER}

The block diagram representation of Unified Power Quality Conditioner is shown in Figure 1. The voltage at PCC may be or may not be distorted depending on the other non-linear loads connected at PCC. This diagram has two converters such as series and shunt which are connected with the common dc link capacitor. First converter is connected shunt with the transmission line at load side commonly called as shunt APF, helps in compensating load harmonic current as well as to maintain dc link voltage at constant level. Another converter is connected in series with utility voltage by series injection transformers called as series converter and it helps in maintaining the load voltage sinusoidal.



Fig 1 single line diagram of UPQC

The controlling technique for series and shunt converter of UPQC is designed based on the block diagram shown in figure 2(a) and 2(b).

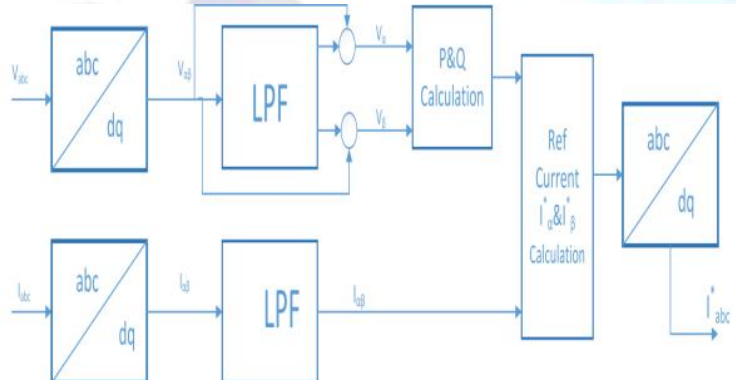

Fig 2(a) Block diagram of overall control structure with Series converter

The series converter, as mentioned in the previous section, is applicable for achieving multi-level control objectives. Hence, the block "function selection and combination" in Fig. 2(a) indicates that different objectives can be integrated into the system by choosing appropriate reference signals [12] isa, is $\beta$, isy. Details about the unbalance correction scheme, which is used to generate current reference for negative-sequence voltage Compensation. For the power control strategy, which are used to obtain desired currents for active/reactive power transfer.

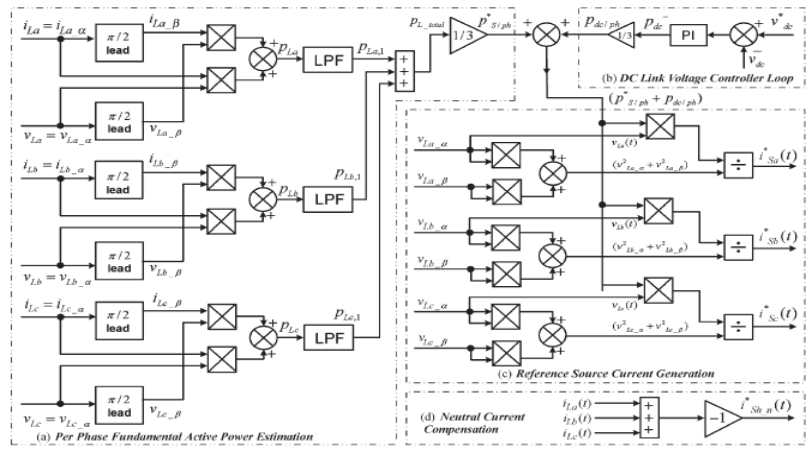

Fig 2(b) Control Diagram Shunt converter

Based on the load on the 3Phase system, the current drawn from the utility can be unbalanced. The current unbalance present in the load currents can be compensated by expanding the concept of single-phase p-q theory. According to this theory, a signal-phase system can be represented in $\alpha-\beta-$ coordinates, and thus, the p-q theory applied for balanced three-phase system can also be used for each phase of unbalanced system independently.

The actual load voltages and load currents are considered as a-axis quantities, whereas the $\pi / 2$ lead load or $\pi / 2$ lag voltages and $\pi / 2$ lead or $\pi / 2$ lag load currents are considered as $\beta$-axis quantities. In this paper, $\pi / 2$ lead is considered to achieve a two-phase system for each phase.

For phase a, the load voltage and current in $\alpha-\beta$ coordinates can be represented by $\pi / 2$ lead as

$$
\begin{array}{r}
{\left[\begin{array}{c}
v_{L a_{\_} \alpha} \\
v_{L b_{-} \beta}
\end{array}\right]=\left[\begin{array}{c}
v_{L a}^{*}(\omega t) \\
v_{L a}^{*}(\omega t+\pi / 2)
\end{array}\right]=\left[\begin{array}{l}
V_{L m} \sin (\omega t) \\
V_{L m} \cos (\omega t)
\end{array}\right]} \\
{\left[\begin{array}{c}
i_{L a_{\_} \alpha} \\
i_{L a_{-} \beta}
\end{array}\right]=\left[\begin{array}{c}
i_{L a}\left(\omega t+\varphi_{L}\right) \\
i_{L a}\left[\left(\omega t+\varphi_{L}\right)+\pi / 2\right.
\end{array}\right]}
\end{array}
$$

Considering phase $a$, the phase- $a$ instantaneous load active and instantaneous load reactive powers can be represented by

$$
\left[\begin{array}{l}
p_{L a} \\
q_{L a}
\end{array}\right]=\left[\begin{array}{cc}
v_{L a_{-} \alpha} & v_{L a_{\_} \beta} \\
-v_{L a_{-} \beta} & v_{L a_{-} \alpha}
\end{array}\right] \cdot\left[\begin{array}{l}
i_{L a_{-} \alpha} \\
i_{L a_{-} \beta}
\end{array}\right]
$$

Where $\quad p_{\mathrm{La}}=\bar{p}_{\mathrm{La}}+\tilde{p}_{\mathrm{La}}, q_{\mathrm{La}}=\bar{q}_{\mathrm{La}}+\tilde{q}_{\mathrm{La}}$

\section{FUZZY LOGIC CONTROLLER}

In the previous section, control strategy based on PI controller is discussed. But in case of PI controller, it has high settling time and has large steady state error. In order to rectify this problem, this paper proposes the application of a fuzzy controller shown in Figure 3. Generally, the FLC is one of the most important software based technique in adaptive methods.

As compared with previous controllers, the FLC has low settling time, low steady state errors. The 
operation of fuzzy controller can be explained in four steps.

1. Fuzzification

2. Membership function

3. Rule-base formation

4. Defuzzification.

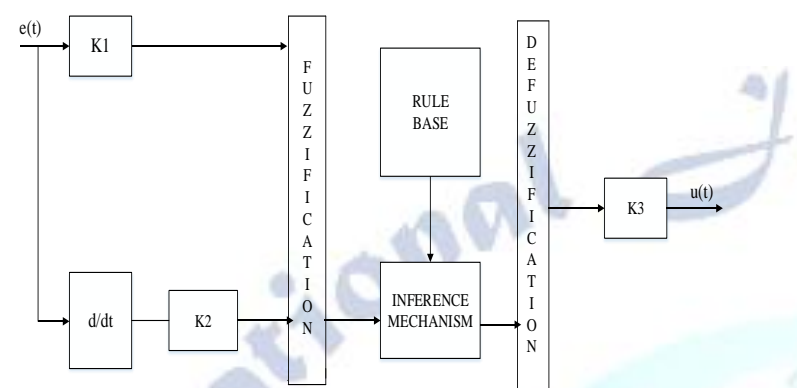

Figure 3: basic structure of fuzzy logic controller

In this paper, the membership function is considered as a type in triangular membership function and method for defuzzification is considered as centroid. The error which is obtained from the comparison of reference and actual values is given to fuzzy inference engine. The input variables such as error and error rate are expressed in terms of fuzzy set with the linguistic terms VN, N, Z, P, and Pin this type of mamdani fuzzy inference system the linguistic terms are expressed using triangular membership functions. In this paper, single input and single output fuzzy inference system is considered. The number of linguistic variables for input and output is assumed as 3.The numbers of rules are formed as 9. The input for the fuzzy system is represented as error of PI controller. The fuzzy rules are obtained with if-then statements.

\section{SIMULATION RESULTS:}

The experimental setup is done in MATLAB/SIMULINK as per the circuit shown in figure 1 .

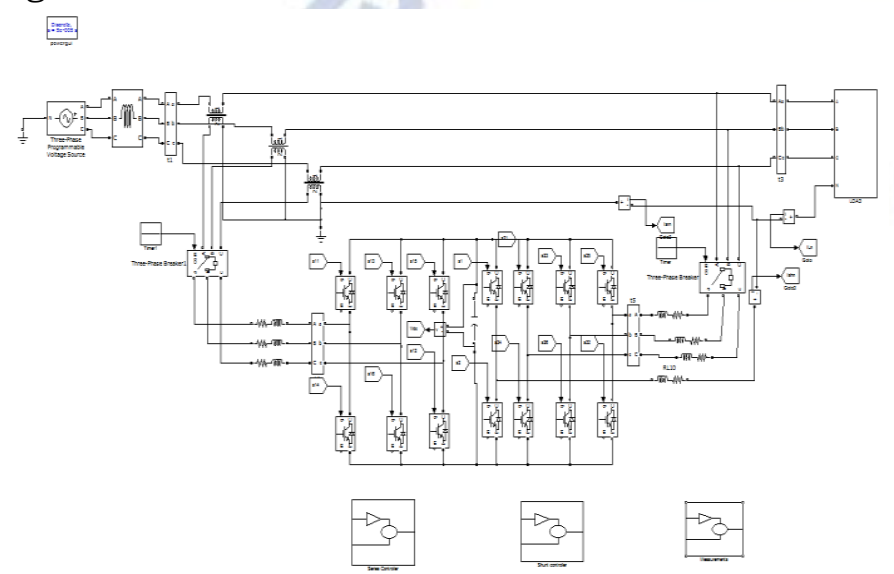

Fig 4: Simulation Diagram of 3P4W UPQC system

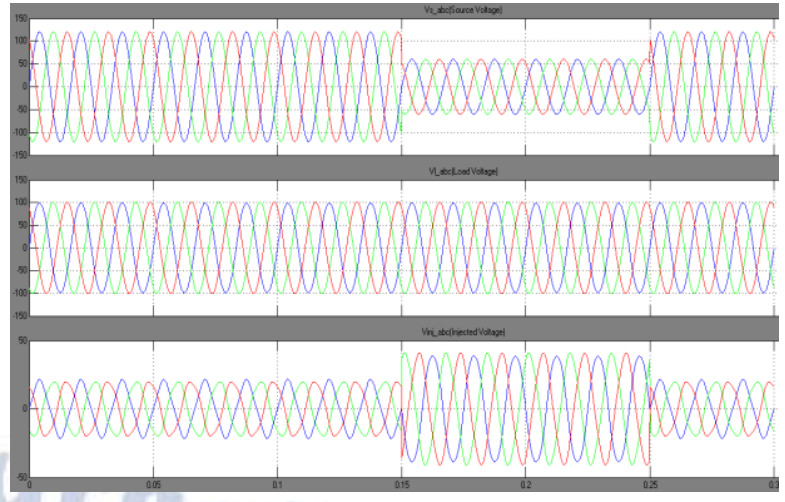

Fig 5 Matlab/Simulink source and load voltages.

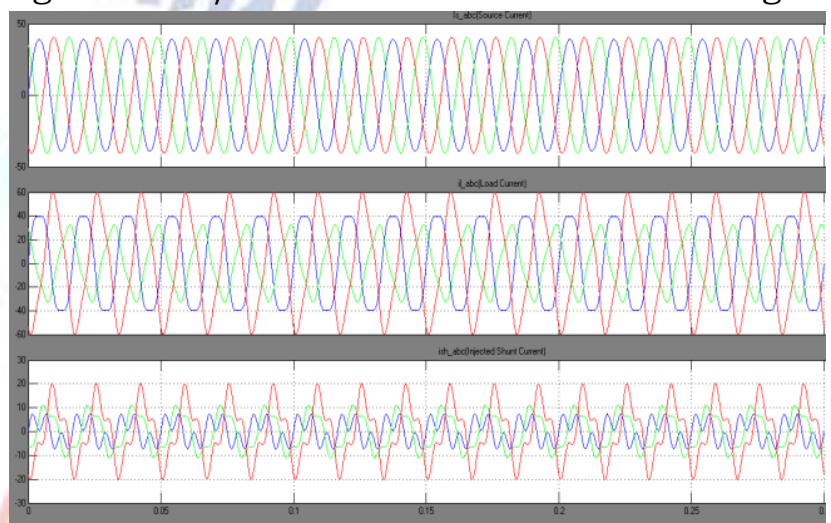

Fig 6 Matlab/Simulink source and load currents.

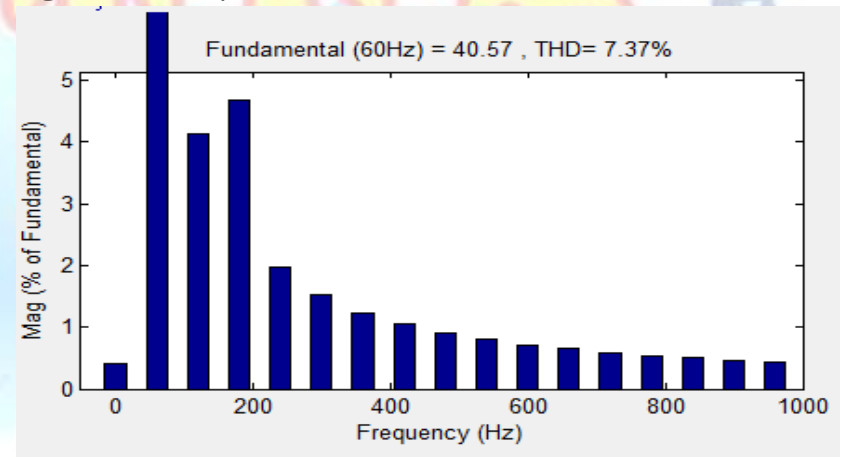

Fig 7: THD for source voltage with PI controller

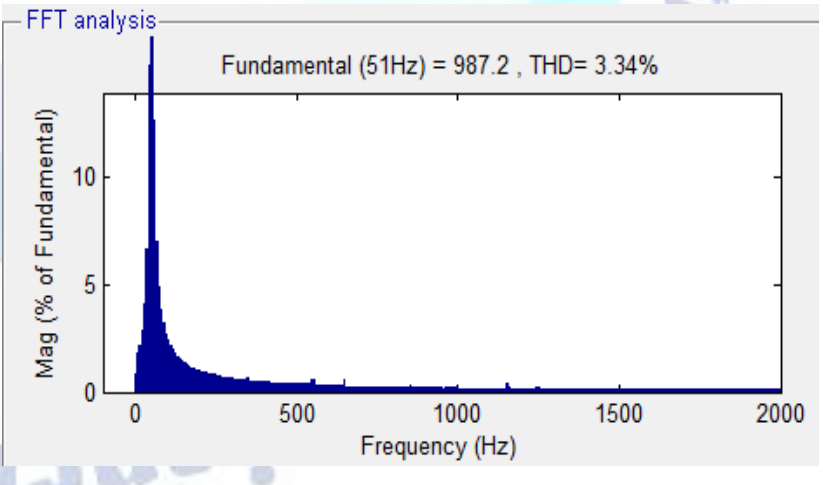

Fig 8: THD for source voltage with Fuzzy controller

Figure 8 and Figure 8 shows the total harmonic distortion values with PI and Fuzzy controllers. From these figure it conclude that the Fuzzy control provide better harmonic distortion factor of load current as compared with conventional PI controller. 


\section{CONCLUSION}

In this paper a 3P4W UPQC is as a multifunction power conditioner which can be used for compensating for the various disturbance in volatge and for preventing the current harmonic.

The Proposed model of unified power quality conditioner has been observed by conducting experiment in MATLAB. A suitable mathematical model of the UPQC developed for designing of series and shunt converter controllers. The fuzzy logic controller is used for getting better performance by the reduction of total harmonic distortion in the system. The simulation results are obtained for the Grid interfacing using series and parallel converter system with conventional PI controller and Fuzzy logic controller. Due to the presence of non-linearity in the system, harmonics are produced which lead to voltage distortions. By using conventional PI controller in the system we can reduce these distortions. However, it is found, through the simulation results, that fuzzy logic controller can do better in reducing harmonics \& improves THD.

\section{REFERENCES}

[1] G.Chen, Y.Chen and K.M.Smeldy, "Three-phase four-leg active power quality conditioner without references calculation, " in Proc.19th IEEE APEC,2004, vol. 1, pp.829-836.

[2] C.A. Quinn and N.Mohan. "Active filtering of harmonic currents in three-phase, four-wire systems with three-phase and single-phase nonlinear loads" in proc. 7th IEEE APEC,1992. Pp. 829-836.

[3] H. Akagi, Y. Kanazawa and A.Nabae, "Instantaneous reactive power compensators comprising switching devices without energy storage components." IEEE Trans. Ind. Appl., vol. 1A-20, no. 3. Pp. 625-630. May/jun. 1984.

[4] Y.Komatsu and T.Kawabata."A control method of active power filter in unsymmetrical and distorted voltage system", in Proc. Conf. IEEE Power Converters., 1997. Vol. 1, pp. 161-168.

[5] M.T.Haque, "Single-phase PQ theory." In Proc. 33rd IEEE PESC,2002,vol.4, pp. 1815-1820.

[6] J.M. Correa, S.Chakraborty, M. G. Simoes, and F.A.Farrent, "A single phase high frequency AC microgrid with an unified power quality conditioner",in Conf. Rec. 38th IEEE Ias Annu. Meeting, 2003, vol. 2, pp. 956-962.

[7] V.Khadkikar, A. Chandra, A.O. Barry, and T.D. Nguyen, "Conceptual analysis of unified power quality conditioner (UPQC).”, in Proc. IEEE ISTE, 2006, pp 1088-1093.

[8] M.Aredes, K.Heumann, and E.H.Watanabe, "An universal active power line conditioner", IEEE Trans. Power Del., vol.13, no. 2, pp. 545-551, Arl.1998.

[9] R. Faranda and I. Valade, "UPQC compensation strategy and design aimed at reducing losses, "in Proc. IEEE ISIE, 2002, vol. 4, pp. 1264-1270. 